\title{
The influence of protein adsorption on interactions of cultured human endothelial cells with polymers
}

\author{
P. B. van Wachem, C. M. Vreriks, T. Beugeling, J. Feijen, A. Bantjes, J. P. Detmers, \\ and W. G. van Aken \\ Department of Chemical Technology, Twente University of Technology, P.O. Box 217, \\ 7500 AE Enschede. The Netherlands, *Hospital Ziekenzorg, Enschede, The Netherlands
}

A systematic study of the effects of polymer surface properties on the interaction with human endothelial cells (HEC) may lead to the development of small-diameter vascular grafts. $\mathrm{HEC}$, suspended in culture medium containing $20 \%$ serum adhered and spread onto moderately wettable polymers such as TCPS (tissue culture polystyrene). Reduced or no adhesion of HEC was observed upon the hydrophobic polymers PETP (polyethyleneterephthalate, Dacron) and FEP (fluoroethylenepropylene copolymer, Teflon). Polymers precoated with the proteins albumin (Alb), high density lipoprotein (HDL), and immunoglobulin $G$ (IgG) inhibited the adhesion of $\mathrm{HEC}$, whereas fibronectin (Fn) coatings promoted cell adhesion. Endothelialization of PETP and FEP only occurred after precoating of these materials with Fn. The adsorption of Fn, Alb, HDL, and IgG from solutions of different serum concentrations onto TCPS, PETP, and FEP was related to the adhesion of HEC. Serum Fn only adsorbed onto TCPS, with the maximum at $0.1 \%$ serum concentration. Maximal cell adhesion onto TCPS was also observed after pretreatment with a solution containing $0.1 \%$ serum. The cell adhesion inhibiting proteins Alb and HDL preferentially adsorbed at higher serum concentrations. Desorption of these proteins and exchange for, e.g., cellular Fn may result in cell spreading and proliferation of HEC upon TCPS.

\section{INTRODUCTION}

In humans, synthetic and processed biological grafts have not been entirely successful in replacing or bypassing small-caliber arteries (5- $\mathrm{mm}$ diameter and smaller). Vascular grafts for replacement of larger blood vessels are employed with a reasonable rate of success, although none or hardly any endothelial lining develops in these grafts. ${ }^{1}$ Since vascular endothelium represents a unique nonthrombogenic surface, endothelialization might, in general, improve the efficacy of grafts. Endothelialization can be promoted by seeding of endothelial cells in the graft during surgery. ${ }^{2,3}$

The development of a complete endothelial lining of the graft inner surface depends on endothelial cell function, flow conditions and polymer surface characteristics such as wettability, charge and roughness. ${ }^{4}$ The importance of polymer surface wettability for cell adhesion was reported in 1960, and was later confirmed in other studies. ${ }^{4,6}$ Cell adhesion preferentially occurs onto water wettable substrates like tissue culture polystyrene (TCPS)

Journal of Biomedical Materials Research, Vol. 21, 701-718 (1987)

(C) 1987 John Wiley \& Sons, Inc.

CCC 0021-9304/87/060701-18\$04.00 
and is promoted by the adsorption of some serum proteins from the culture medium.

The adsorption of serum derived fibronectin (which is slightly different from the cellular fibronectin ${ }^{9}$ ) onto various substrates has been shown to depend on the wettability of the surfaces and on the serum concentration of the culture medium. ${ }^{10-19}$ Competition between the adsorption of fibronectin (Fn) and other serum proteins such as albumin (Alb), immunoglobulin $G$ (IgG), lipoproteins, ${ }^{4,18} \alpha$-1-antitrypsin and $\alpha$-2-macroglobulin ${ }^{18}$ may explain the dependence of Fn adsorption on the serum concentration.

In the absence of serum proteins, cell adhesion onto surfaces is promoted by the cellular secretion of protein(s) like Fn. ${ }^{7,8}$

As reported before, ${ }^{20}$ human endothelial cells (HEC) adhere, spread and proliferate on(to) TCPS, when seeded in culture medium containing $20 \%$ human serum. However, reduced or no adhesion of HEC is observed upon polyethyleneterephthalate (PETP, Dacron) and fluoroethylenepropylene copolymer (FEP, Teflon) respectively. We have suggested that the observed differences in HEC adhesion onto TCPS, PETP, and FEP is due to differences in the surface wettability of these polymers; this in turn results in qualitative and quantitative variations in the composition of the adsorbed protein layer.

We have previously shown that the adhesion of HEC onto "uncoated" or serum precoated PETP increased after the pretreatment of this material with Fn, fibrinogen $(\mathrm{Fb})$ or plasma. ${ }^{21} \mathrm{Alb}$, high-density lipoprotein (HDL) and IgG precoating of PETP inhibited the HEC adhesion.

In this article we present data regarding the relationship between protein adsorption to TCPS, PETP, and FEP and the interaction with HEC. The effect of protein precoating of these polymers on subsequent adhesion and proliferation of HEC was investigated. Furthermore, the adsorption of Fn, Alb, HDL, and IgG from solutions of different serum concentrations was studied by means of an enzyme immunoassay (EIA ${ }^{22,23}$ ). The composition of the adsorbed protein layer on these surfaces was related to the adhesion of HEC.

\section{MATERIALS AND METHODS}

\section{Materials}

Tissue culture polystyrene (TCPS) was obtained from Costar, Cambridge, MA, USA. Cellular interaction studies were carried out with six-well tissue culture clusters (each well has a test surface area of $10 \mathrm{~cm}^{2}$ ); 24 -well tissue culture clusters were used for protein adsorption studies (with a test surface area of $2 \mathrm{~cm}^{2}$ per well). Polyethyleneterephthalate (PETP, Melinex polyester film, type O) was obtained from ICI, Rotterdam, The Netherlands. Fluoroethylenepropylene copolymer (FEP, film type 500A) was purchased from Du Pont de Nemours, Geneva, Switzerland. 
Proteins used for precoating of the materials

Crude fibronectin, $\left(\mathrm{Fn}^{c}\right.$, coproduct from cryoprecipitate preparation of coagulation factor VIII, $2 \%$ solution $(w / v)$ in complete medium) was obtained from the Central Laboratory of the Netherlands Red Cross Blood Transfusion Service (CLB), Amsterdam, The Netherlands. Because substrata, used for the routine culture of $\mathrm{HEC}$, are precoated with this fibronectin preparation (see Methods) the effects of other proteins on the cell adhesion (proliferation) were compared with the effect of $\mathrm{Fn}^{c}$. However, $\mathrm{Fn}^{c}$ may contain fibrinogen and for this reason it was also purified (Fn) as described by Ruoslahti et al. ${ }^{24}$ Fn was dissolved in phosphate buffered saline (PBS) $(50 \mu \mathrm{g} / \mathrm{mL})$.

Human serum albumin (Alb, 20\% solution $(w / v)$ ) and immunoglobulin $G$ (IgG, 6\% solution $(w / v)$ ) were also obtained from CLB.

High-density lipoprotein (HDL, $100 \mu \mathrm{g} / \mathrm{mL}$ medium M199, see below), was a gift of Dr. V.W.M. van Hinsbergh, Gaubius Institute, Leiden, The Netherlands. HDL was obtained from one male blood donor and dialyzed twice against phosphate buffered saline (PBS, obtained from NPBI, EmmerCompascuum, the Netherlands) and medium M199 (from Gibco Biocult Co., Paisley, U.K).

Fibrinogen $(\mathrm{Fb}, 50 \mu \mathrm{g} / \mathrm{mL}$ in $\mathrm{PBS})$ was purchased from $\mathrm{AB}$ Kabi, Stockholm, Sweden.

CPDAl-plasma (further called plasma), pooled from 6 healthy male donors and whole blood serum (further called serum, pool of 20 healthy male donors) were obtained from the Red Cross Bloodbank Twente, Enschede, The Netherlands.

Buffers and proteins used for protein adsorption studies

PBS, supplemented with $0.005 \%$ Tween-20 (obtained from Sigma, St. Louis, MO, USA) was used as washing buffer in the protein adsorption studies. For the enzyme immunoassay (for the subsequent steps, see Methods) the following buffers were used. First antibody buffer consisted of $8.7 \mathrm{~g} / \mathrm{L} \mathrm{NaCl}, 6.1 \mathrm{~g} / \mathrm{L}$ Tris (Merck, Darmstadt, FRG), 0.02\% (v/v) Tween-20, $0.21 \%(w / v)$ gelatin (Merck) and $0.5 \%(w / v)$ bovine serum albumin (BSA, obtained from Sigma) with $\mathrm{pH}$ adjusted to 7.5. The conjugate buffer had the same composition as the first antibody buffer except for the concentration of BSA which was $5 \%$.

The leuko dye solution consisted of $100 \mathrm{mmol} / \mathrm{L}$ sodium acetate, $\mathrm{pH}=5.5$ and $165 \mu \mathrm{L} \mathrm{3,} \mathrm{3,} \mathrm{5,} \mathrm{5-tetramethyl} \mathrm{benzidine} \mathrm{(Fluka} \mathrm{AG,} \mathrm{Buchs,} \mathrm{Switzerland).}$ To $10 \mathrm{~mL}$ of this solution $10 \mu \mathrm{L}$ of a $3 \%$ peroxide solution (Merck) as the enzyme substrate were added.

Rabbit sera directed against human Fn, human Alb, and human IgG were obtained from CLB. These antisera were diluted 100 -fold with first antibody 
buffer. The antiserum against human HDL, i.e., against apoprotein A-1 of HDL, was purchased from Behringwerke AG (Marburg, FRG) and diluted 10 -fold with first antibody buffer.

Sheep antirabbit IgG (SKIgG), covalently bound to horse radish peroxidase was obtained from United States Biochemical Co. (Cleveland, OH, USA). Unlabeled SKIgG was purchased from CLB. SKIgG was diluted 200-fold with unlabeled SKIgG, followed by a 1000-fold dilution with conjugate buffer.

\section{Methods}

\section{Cell culture, adhesion, and proliferation}

Endothelial cells were isolated from human umbilical cord veins according to the method originally described by Jaffe et al. ${ }^{24}$ with some modifications. ${ }^{25}$

After isolation, endothelial cells were cultured and subcultured, when confluent, in TCPS flasks (Corning, NY, USA) precoated with partially purified fibronectin ( $\mathrm{Fn}^{c}$; see above). The endothelial origin of the cultured cells was identified by their polygonal morphology and the secretion of von Willebrand factor (see below).

The culture medium consisted of complete medium, which is an equal mixture of Medium M 199 and Medium RPMI 1640 (both from Gibco Biocult Co., Paisley, U.K.), with $2 \mathrm{mM}$ L-glutamine (Merck), $100 \mathrm{U} / \mathrm{mL}$ penicillin, $100 \mu \mathrm{g} / \mathrm{mL}$ streptomycin (both from Flow Lab., Irvine, U.K.) and $2.5 \mu \mathrm{g} / \mathrm{mL}$ fungizone (Gibco), which was supplemented with $20 \%$ human serum.

For adhesion and proliferation experiments cells were used after the second or third passage when cultures had reached confluence. Harvesting of cells for subcultures and for experiments was performed by trypsinization ( $0.05 \%$ trypsin $/ 0.02 \%$ EDTA). Thereafter, trypsin was inactivated by the addition of culture medium containing $20 \%$ serum. Cell counting (by means of a hemocytometer) was performed after incubation of the adhering cells with trypsin solutions of different concentrations (concentrations between $0.05 \%$ and $0.5 \%$ ).

Adhesion of HEC onto polymeric surfaces was determined at 30 minutes, 1,2 , and $6 \mathrm{~h}$ after seeding $4 \times 10^{4}$ cells $/ \mathrm{cm}^{2}$ in the presence of culture medium containing $20 \%$ serum. ${ }^{20}$ In order to determine the adhesion of HEC onto surfaces in serum-free medium, the cells were washed three times with complete medium before seeding in the same medium; adherent cells were counted at $30 \mathrm{~min}$.

Proliferation of HEC on surfaces was studied for 8 days after seeding at a density of $1 \times 10^{4}$ cells $/ \mathrm{cm}^{2}$. Refreshment of culture medium and cell counts were performed at 2-day intervals.

Data are presented as the mean values of three counts and are either expressed as number of cells $/ \mathrm{cm}^{2}$ or as the percentage of cells ( \pm S.D.) adhering onto TCPS precoated with $\mathrm{Fn}^{c}$ (reference surface).

Secretory functions of HEC, which had grown to confluence upon different surfaces, were investigated. The production of the endothelial marker 
von Willebrand factor ${ }^{25}$ and of prostacyclin were measured as follows. HEC were washed twice with RPMI-1640 and incubated for $1 \mathrm{hr}$ with serum-free medium (control) or serum-free medium supplemented with $10 \mu \mathrm{m}$ $\mathrm{Ca}^{2+}$-ionophore A23187 (Boeringer, Mannheim, FRG). The serum-free medium consisted of an equal mixture of Medium-199 and RPMI-1640, 1\% (w/v) human serum albumin (CLB), $10 \mu \mathrm{g} / \mathrm{mL}$ insulin from bovine pancreas (Sigma, St. Louis, USA), $20 \mu \mathrm{g} / \mathrm{mL}$ transferrin (Sigma) and the antibiotics mentioned above. ${ }^{28}$ Von Willebrand factor was measured in the cell supernate as antigen in an immunoradiometric assay according to Ruggeri et al. ${ }^{29}$ with some modifications including the use of monoclonal antibody to von Willebrand factor. ${ }^{30}$ Prostacyclin was measured as its stable hydrolysis product 6-keto-prostaglandin-F1 $\alpha$ by radioimmunoassay, using antiserum kindly provided by Dr. J. A. Salmon (Wellcome Research, Beckenham, U.K.). ${ }^{31}$ The values of von Willebrand factor and 6-keto PGF1 $\alpha$ are the mean of three incubations.

Specimens of PETP and FEP, used for both the study of cellular interactions and protein adsorption, were cleaned ultrasonically with a $1 \%$ detergent solution (RBS 25, Hicol, Rotterdam, The Netherlands) for $30 \mathrm{~min}$, followed by extensive rinsing with distilled water and ethanol. After drying, the specimens were either mounted in a modified "Bionique" growth chamber (Corning, NY, USA), ${ }^{20}$ that was used for the study of cellular interactions, or in a specially constructed 24-well chamber used for the protein adsorption studies (each well has a test surface area of $1 \mathrm{~cm}^{2}$ ). For cell proliferation studies the films of PETP and FEP were sterilized by autoclaving. This treatment did not alter the surface wettability of the materials, as measured by the captive bubble method. ${ }^{20}$ TCPS, in the form of 24 well-clusters, was used as received from the manufacturer.

The ratio of the volume of the protein solution $(\mathrm{mL})$, used for precoating of the materials, to the apparent polymeric surface area $\left(\mathrm{cm}^{2}\right)$ was 0.2 . Protein precoating was carried out for one hour at room temperature. Thereafter, the protein solution was removed and the wells of the growth chambers or 24-well chambers were washed with PBS.

\section{Protein adsorption studies}

Protein adsorption to polymer surfaces was studied by means of a two step enzyme immunoassay (EIA) which permits the selective detection of $\mathrm{Fn}$, $\mathrm{Alb}, \mathrm{HDL}$ and IgG. ${ }^{22,23}$ The EIA was modified from a 96-well-plate assay to a 24-well-plate assay in order to measure protein adsorption to polymeric films such as PETP and FEP.

Briefly, for each well the following assay procedure was employed: First, $200 \mu \mathrm{L} / \mathrm{cm}^{2}$ of protein solution or PBS (used as a blank) was applied. After one hour the protein solution was removed and the test surfaces were rinsed three times with washing buffer. This washing procedure was also carried out after the subsequent steps. Then $200 \mu \mathrm{L} / \mathrm{cm}^{2}$ of first antibody solution was added, followed by $200 \mu \mathrm{L} / \mathrm{cm}^{2}$ of enzyme labeled second antibody 
(contact time in both cases $1 \mathrm{hr}$ ). The enzymatic (color) reaction started after the addition of $200 \mu \mathrm{L} / \mathrm{cm}^{2}$ of substrate and leuko dye solution. The reaction was carried out in the dark during $30 \mathrm{~min}$ and was terminated by the addition of $100 \mu \mathrm{L} / \mathrm{cm}^{2}$ of $4 \mathrm{~N}$ sulphuric acid. Part of the dye solution $(250 \mu \mathrm{L})$ was pipetted into a 96-well-plate (A/S Nunc, Roskilde, Denmark) and the absorbance was measured at $450 \mathrm{~nm}(\mathrm{~A}-450)$ with a multiscanner (Reader Micro Elisa System, Organon Teknika, Turnhout, Belgium). When the absorbance exceeded the value of 2.0 , the test samples were diluted before measurement.

The data, presented as relative protein adsorptions, are the mean values of three measurements ( \pm S.D.) and based on measured extinction coefficients.

\section{RESULTS}

\section{Cell adhesion and proliferation in serum-containing medium onto materials precoated with protein solutions}

Polymer surfaces precoated with $\mathrm{Fn}^{c}, \mathrm{Fn}, \mathrm{Fb}$, or plasma generally demonstrated increased numbers of adherent cells as compared to the noncoated materials (Figs. 1, 2, and 3). At $30 \mathrm{~min}$, cell adhesion to TCPS precoated with $\mathrm{Fb}$ or plasma was slightly less when compared with $\mathrm{Fn}^{\mathrm{c}}$ - or Fn-precoated TCPS; serum precoating of TCPS resulted in an adhesion rate similar to that of the $\mathrm{Fb}$ precoated surface (Fig. 1).

Alb, HDL, and IgG were found to delay the adhesion to TCPS during the first hour after cell seeding (Fig. 1). After 6 hr the number of adherent cells was about the same, whether or not TCPS was precoated with one of these proteins. All adherent cells had completely spread.

Precoating of PETP with serum showed no difference in cell adhesion as compared to the uncoated surface (Fig. 2). Microscopically, the adhering cells showed a "spiderlike" structure, quite distinct from the progressive flattening of cells occurring upon TCPS. The inhibition of cell adhesion by Alb, HDL and IgG preadsorbed onto PETP (Fig. 2) continued for at least $6 \mathrm{hr}$ : some cell adhesion was observed, but complete spreading of cells did not occur. Increased cell adhesion, followed by progressive flattening, occurred after precoating of PETP with $\mathrm{Fn}^{c}, \mathrm{Fn}, \mathrm{Fb}$, or plasma.

Cell adhesion onto FEP only occurred after precoating of $\mathrm{FEP}$ with $\mathrm{Fn}^{c}, \mathrm{Fn}$, $\mathrm{Fb}$, or plasma (Fig. 3). Adhesion upon these surfaces was followed by cell spreading. HEC did not adhere onto uncoated, serum-, Alb-, HDL-, or IgGprecoated FEP.

Cell proliferation was examined during 8 days. Cells proliferated upon TCPS, whether it was precoated with a protein solution or not. Proliferation only occurred on PETP and FEP, when these polymers were precoated with $\mathrm{Fn}^{c}, \mathrm{Fn}, \mathrm{Fb}$, or plasma. The proliferation rates on these surfaces were similar as compared to the proliferation of cells on the reference surface (TCPS-Fn') 


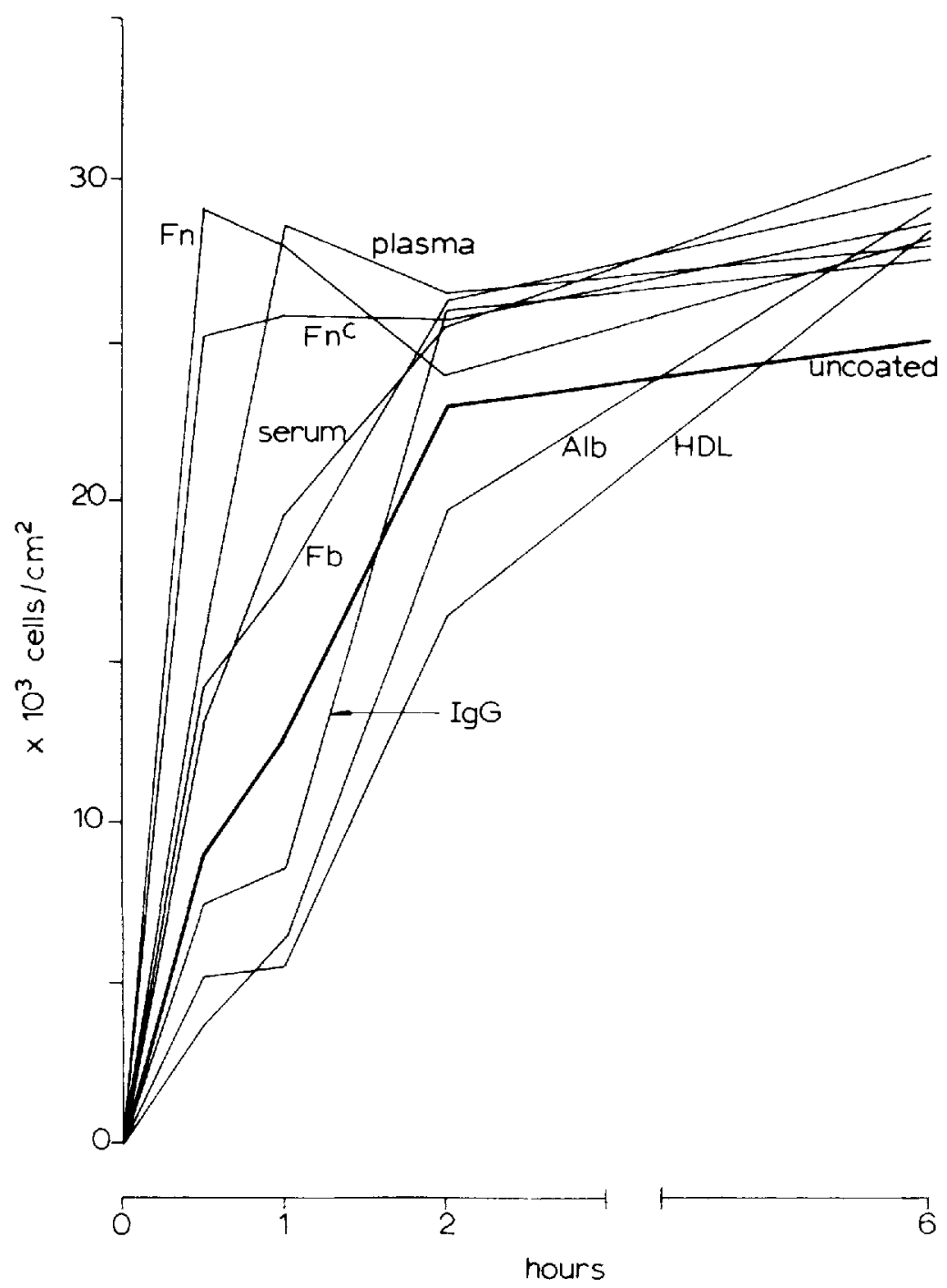

Figure 1. Adhesion of HEC $\left(X 10^{3}\right.$ cells $\left./ \mathrm{cm}^{2}\right)$ to uncoated and protein precoated TCPS. $4 \times 10^{4}$ cells $/ \mathrm{cm}^{2}$ were seeded in culture medium containing $20 \%$ serum. Cell counts were performed at $30 \mathrm{~min}$ and 1,2 , and $6 \mathrm{hr}$.

(Fig. 4). Confluent HEC, stimulated by the $\mathrm{Ca}^{2+}$-ionophore A23187, released similar values of von Willebrand factor and prostacyclin as compared with confluent HEC upon the reference surface (Table I). The production of von Willebrand factor and prostacyclin by HEC on surfaces precoated with Fn was higher than that of HEC on Fb-precoated surfaces. 


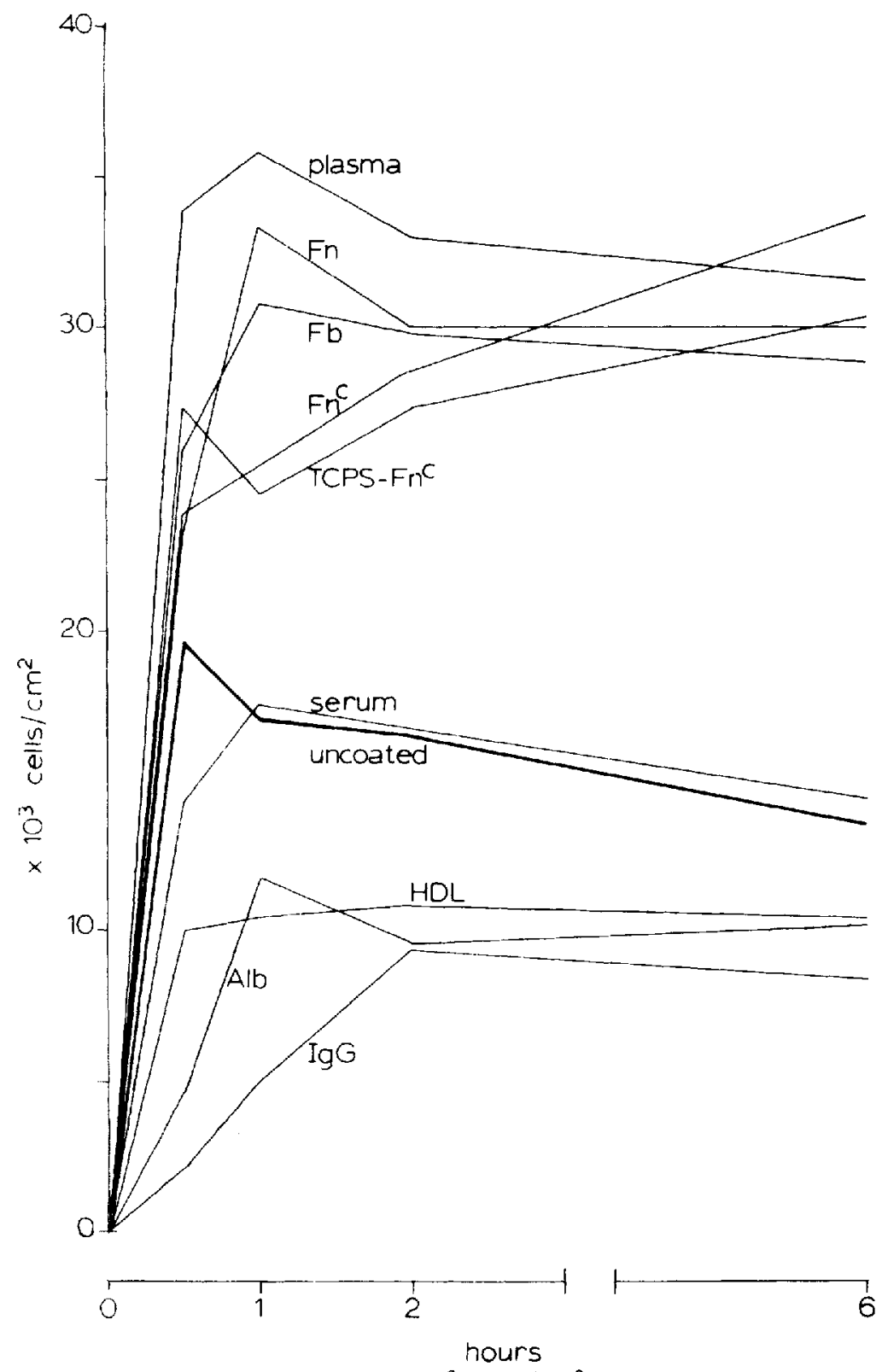

Figure 2. Adhesion of $\mathrm{HEC}\left(X 10^{3}\right.$ cells $\left./ \mathrm{cm}^{2}\right)$ to uncoated and protein precoated PETP. For protein concentrations, see Materials and Methods. $4 \times 10^{4}$ cells $/ \mathrm{cm}^{2}$ were seeded in culture medium containing $20 \%$ serum. Cell counts were performed at $30 \mathrm{~min}$ and 1,2 , and $6 \mathrm{hr}$. 


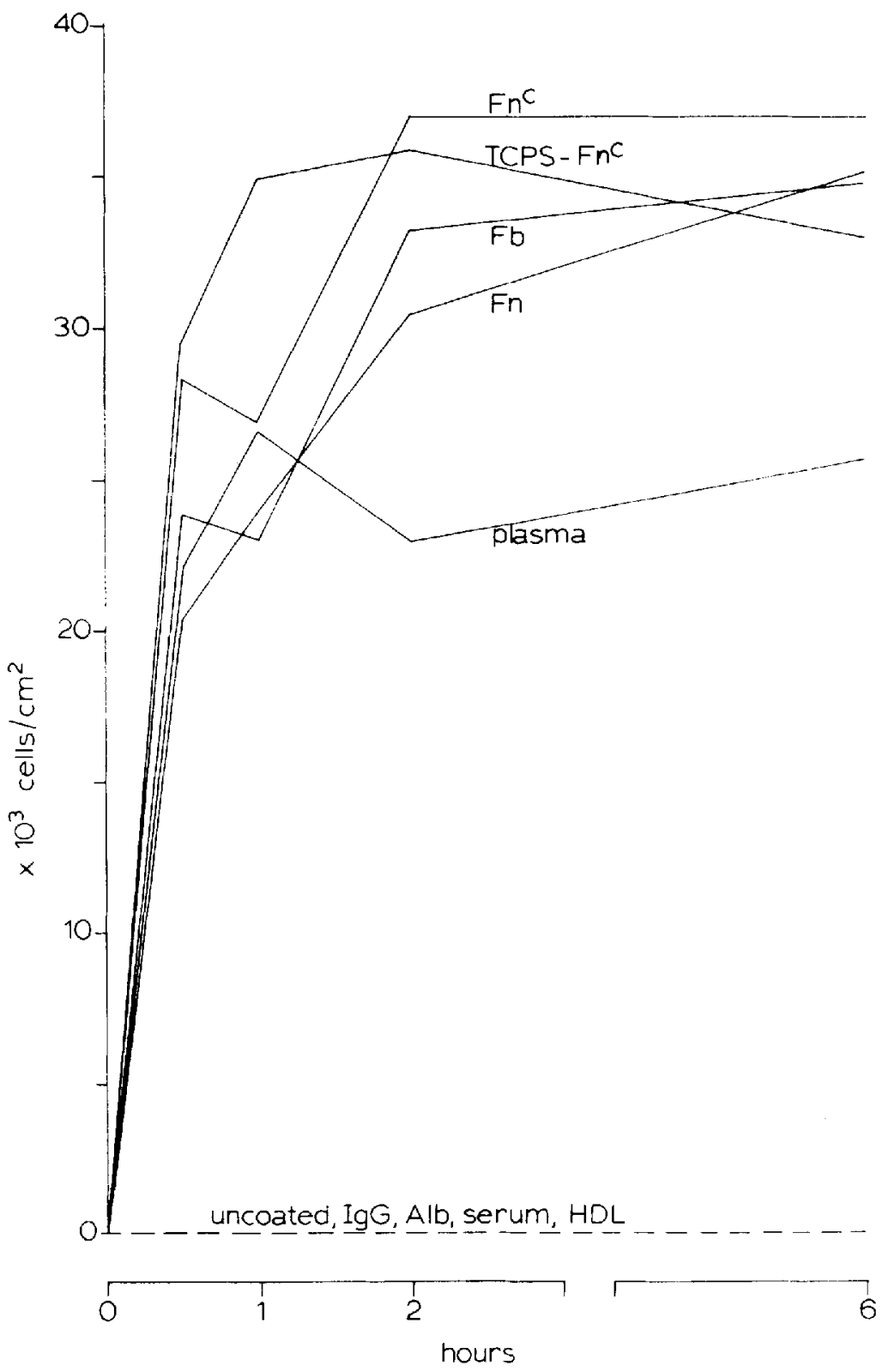

Figure 3. Adhesion of HEC onto uncoated and protein precoated FEP. The reference surface was TCPS precoated with $\mathrm{Fn}^{c} .4 \times 10^{4}$ cells $/ \mathrm{cm}^{2}$ in $20 \%$ serum-containing culture medium were seeded upon the test surfaces. Cell counts were carried out at $30 \mathrm{~min}$ and 1, 2, and $6 \mathrm{hr}$. For protein concentrations, see Materials and Methods. 


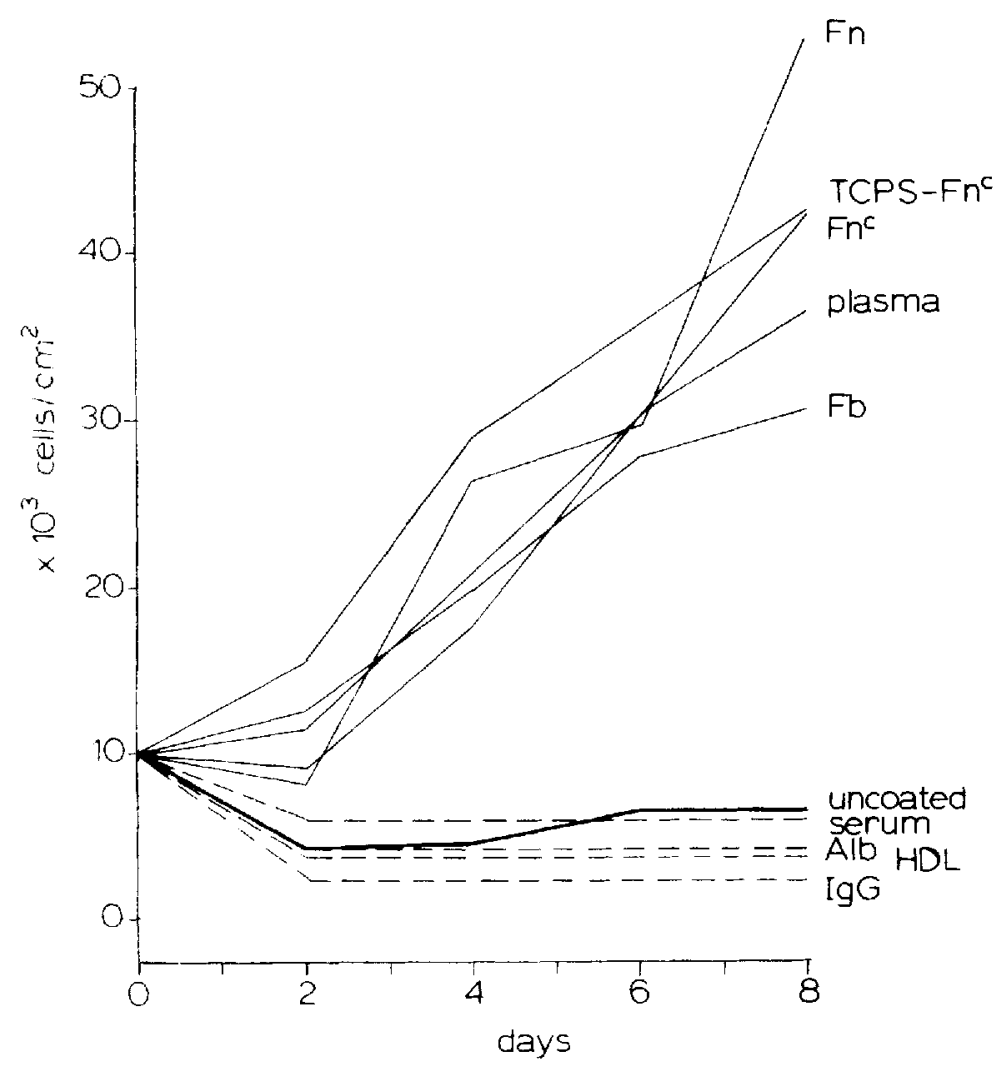

Figure 4. Proliferation of HEC $\left(X 10^{3}\right.$ cells $\left./ \mathrm{cm}^{2}\right)$ on uncoated and protein precoated PETP. For protein concentrations, see Materials and Methods. $1 \times 10^{4}$ cells $/ \mathrm{cm}^{2}$ were seeded in culture medium containing $20 \%$ serum. Cell counts and refreshing of the culture medium were carried out at 2, 4,6, and 8 days. The ratio of the culture medium volume to the surface area was $0.2 \mathrm{~mL} / \mathrm{cm}^{2}$.

\section{Adsorption of Fn, Alb, HDL, and IgG onto polymer surfaces from solutions of different serum concentrations}

The differences in cell adhesion, observed when Fn, Alb, HDL, or IgG was used for precoating, prompted the study of the adsorption of these proteins from serum-containing culture medium. Different serum concentrations were obtained by dilution of the serum-containing culture medium with PBS. Subsequently, TCPS, PETP, and FEP were exposed to solutions of different serum concentrations for one hour. The protein adsorption data are shown in Figures 5 and 6.

Figure 5 shows the differences in Fn adsorption between the three materials. Maximal adsorption of Fn was observed upon TCPS at a concentration of $0.1 \%$ serum. Relatively small amounts of Fn were detected upon PETP and FEP. Both materials showed a small increase in the adsorption of Fn at a concentration of $0.1 \%$ serum. 
TABLE I

Effect of $10 \mu \mathrm{M} \mathrm{Ca}{ }^{2+}$-ionophore A23187 on the Secretion (ng/10 cells) of von Willebrand Factor and Prostacyclin (6-Keto-PGF1a) by Confluent HEC

\begin{tabular}{lccccc}
\hline & \multicolumn{2}{c}{ von Willebrand factor } & & \multicolumn{2}{c}{ Prostacyclin } \\
\cline { 2 - 3 } \cline { 5 - 6 } Surface & Control & A23187 & & Control & A23187 \\
\hline TCPS-Fn $^{c}$ & 202 & 444 & 30 & 268 \\
TCPS-uncoated & 362 & 469 & 38 & 182 \\
TCPS-Fn & 338 & 827 & 54 & 422 \\
TCPS-Fb & 289 & 571 & 18 & 155 \\
PETP-Fn & 249 & 357 & 30 & 192 \\
PETP-Fb & 132 & 245 & 13 & 82 \\
FEP-Fn & 135 & 314 & 33 & 310 \\
FEP-Fb & 143 & 264 & 20 & 152 \\
\hline
\end{tabular}

Similarly to Fn, IgG reached maximum adsorption onto TCPS at $0.1 \%$ serum concentration (Fig. 5b). An increase in the adsorption of Alb and HDL onto TCPS occurred with increasing serum concentrations (Fig. 5c, d).

Smaller amounts of Alb, HDL and IgG were detected upon PETP; the HDL adsorption increased with increasing serum concentration while maximal adsorptions of $\mathrm{Alb}$ and $\mathrm{IgG}$ were found at 0.01 and $0.1 \%$ serum, respectively. Relatively small amounts of these proteins adsorbed onto FEP (Fig. 5b, c, d).

\section{Cell adhesion under serum-free conditions onto surfaces preexposed to solutions of different serum concentrations}

The adhesion of HEC onto surfaces preexposed to solutions of different serum concentrations was measured after $30 \mathrm{~min}$. In order to prevent an exchange of adsorbed proteins for proteins present in the culture medium, HEC were seeded under serum-free conditions. HEC adhesion onto TCPS varied between about 50 and $100 \%$, as compared to the adhesion observed onto TCPS precoated with $\mathrm{Fn}^{c}$ (Fig. 6); maximal adhesion of HEC occurred after pretreatment of TCPS with $0.1 \%$ serum. A strong decrease in HEC adhesion was observed when TCPS was exposed to 1 and 10\% serum. The course of this adhesion curve more or less corresponds with the adsorption isotherm of Fn, as is also shown in Figure 6. At low serum concentrations no cell spreading was observed using the light microscope. Especially the nonspreading HEC hardly detached after (mild) trypsinization. Therefore, a more concentrated trypsin solution was used for the detachment of these cells. The same treatment was used for detachment of cells from uncoated PETP. Pretreatment of TCPS with solutions containing increasing amounts of serum resulted in increased cell spreading.

HEC adhesion onto PETP varied between 10 and $40 \%$ of the cellular adhesion observed onto the reference surface (not shown). Minimal adhesion of HEC occurred to PETP pretreated with 1 or $10 \%$ serum. Cell spreading did not occur after exposure of PETP to solutions of low serum concentrations. 

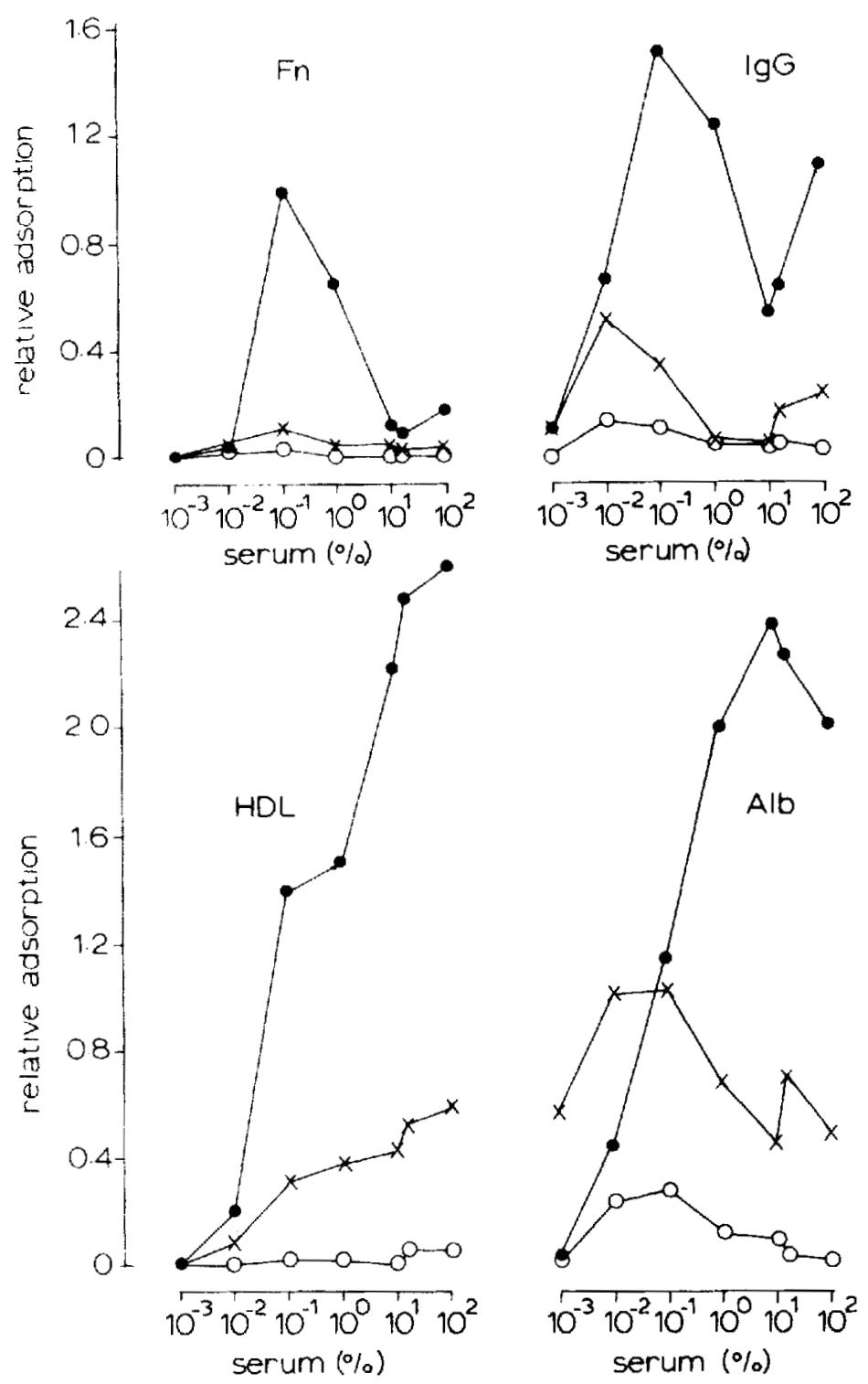

Figure 5. Relative protein adsorption onto $\bullet$ TCPS, $\times$ PETP and $O$ FEP from solutions of different serum concentrations, as measured after a contact time of $1 \mathrm{hr}$ (5a: Fn, 5b: IgG, 5c: HDL, 5d: Alb).

Moreover, cell spreading was still incomplete after exposure of PETP to solutions of higher serum concentrations.

Hardly any cell adhesion occurred upon FEP, irrespective of the serum concentration in the solution used for precoating. 


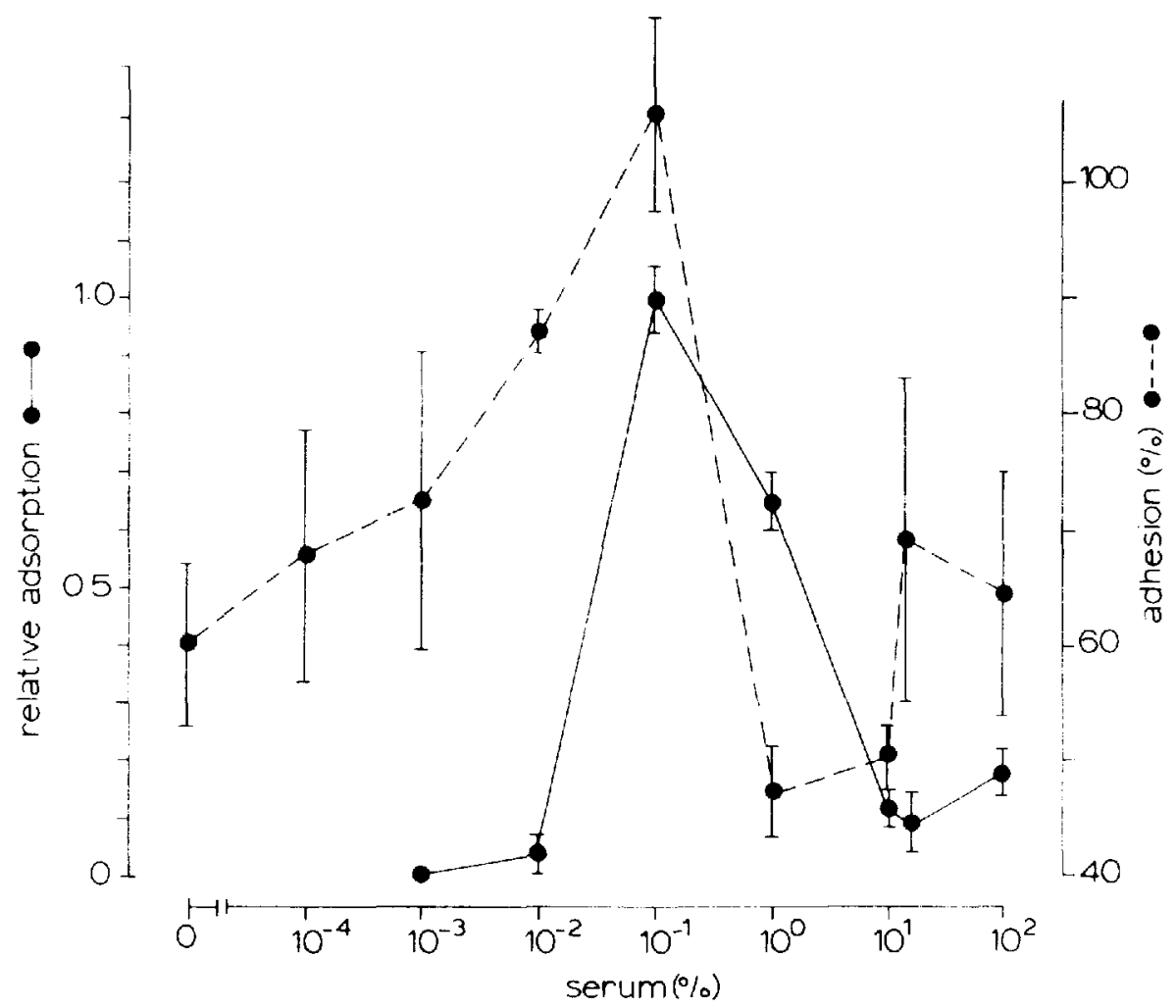

Figure 6. Relative adsorption of fibronectin and adhesion of HEC onto TCPS. Protein adsorption from solutions of different serum concentrations was measured after a contact time of $1 \mathrm{hr}$. The adhesion of HEC was measured under serum-free conditions after $30 \mathrm{~min}$ and compared with the adhesion of HEC to TCPS precoated with $\mathrm{Fn}^{\mathrm{c}}$.

\section{DISCUSSION}

This study demonstrates that coverage of the (more) hydrophobic materials PETP and FEP by endothelial cells only occurred after precoating of these materials with $\mathrm{Fn}^{\mathrm{c}}$, Fb or plasma (Figs. 1, 2, and 3). Surface precoating with these proteins was not a prerequisite for proliferation of $\mathrm{HEC}$ on the moderately wettable TCPS, although the adhesion of HEC on this material was accelerated during the first $2 \mathrm{hr}$ after pretreatment with these proteins (Fig. 1). Cells, which had proliferated to confluency upon the different surfaces, were positively identified as endothelial cells by their secretion of von Willebrand Factor. Confluent HEC also produced prostacyclin (Table I).

The results concerning the adhesion of HEC onto protein precoated TCPS and PETP (Figs. 1, 2) were analyzed statistically in order to determine whether the observed differences in cell adhesion were caused by the type of protein used for precoating. The following linear model was used for 
the analysis:

$$
\begin{aligned}
\text { Adhesion }= & \text { constant }+ \text { time }+ \text { type of protein } \\
& + \text { time } \times \text { type of protein }
\end{aligned}
$$

where the type of protein was a categorical variable and time a regression variable. In this type of experiments the variability of all experiments is typically much larger than the variability within three counts at the specified times, which gives the appropriate error term for statistical significance. The experiments should therefore be analyzed in primarily quantitative terms, as only the strong effects can be expected to generalize to other experiments.

The significance of all factors was found to be much higher when tested against the variance within three counts at the specified times, which ranged from 5-10\% of the total variance. Quantitatively, the main result with respect to TCPS (Fig. 1) is, that the course of adhesion over time on this surface depends on the precoating. Alb, HDL, IgG, and uncoated TCPS show a relatively low initial adhesion, compared to $\mathrm{Fn}^{(c)}, \mathrm{Fb}$, plasma and serum. A different pattern is observed with PETP (Fig. 2) where the main effect is that adhesion as such, irrespective of time, varies as a function of precoating. Alb, HDL and IgG show the lowest adhesion, followed by serum precoated and uncoated PETP.

In contrast with PETP and FEP protein desorption from the (moderately wettable) TCPS may have occurred. ${ }^{19}$ Fn, from the serum-containing culture medium or from cellular origin, may have replaced preadsorbed Alb, HDL, and IgG. Preliminary studies indicate that the deposition of cellular $\mathrm{Fn}$ is more important than the adsorption of Fn from the serumcontaining culture medium. Other adhesive proteins, such as vitronectin, ${ }^{33-35}$ von Willebrand factor and thrombospondin ${ }^{36,37}$ are possibly also involved in the adhesion of HEC.

Our results also show that the adsorption of serum Fn onto polymer surfaces strongly promotes the adhesion of HEC (Figs. 5a, 6). This protein adsorbed onto TCPS from serum and solutions of various serum concentrations. Only small amounts of Fn could be detected on PETP and FEP (Fig. 5a). Evidently the affinity of Fn for FEP is too small to allow HEC to adhere to this polymer surface. PETP which is less hydrophobic than FEP possibly adsorbs more Fn than FEP, although this conclusion can hardly be drawn from Figure 5a. If more Fn adsorbs to PETP compared to FEP it may account for the fact that some HEC adhesion to PETP takes place.

It must be mentioned here that one limitation of the applied enzymeimmunoassay is that the interaction of the antibodies with adsorbed proteins may be affected by the orientation in which the proteins adsorb onto different polymer surfaces. Moreover, during the adsorption process conformational changes of protein molecules may occur. Therefore, differences in reactivity toward antibody molecules may take place. Consequently, small differences in absorbances of the generated dye, measured for the adsorption of a protein to different materials, do not automatically imply that differences in adsorbed amounts of protein really exist. 
Our Fn-adsorption results are in accordance with published data showing the higher affinity of Fn for (moderately) wettable polymers as compared to more hydrophobic polymers. ${ }^{10-12,15,17,18,32}$ We found maximal $\mathrm{Fn}$ adsorption on TCPS (Figs. 5,6 ) at a serum concentration of $0.1 \%$, which is in agreement with other reports. ${ }^{10-12,14}$ Grinnell ${ }^{11}$ suggested that low concentrations of plasma proteins may enhance the affinity of Fn for surface adsorption sites by influencing the orientation in which Fn adsorbs. Preferential adsorption of $\mathrm{Alb}$ and HDL onto TCPS from solutions of serum concentrations above $0.1 \%$, may explain the decrease of Fn adsorption and possibly as a result a diminished adhesion of HEC. The fact that Fn adsorbed to TCPS from the undiluted culture medium in which large amounts of other serum proteins are present, indicates that this polymer shows a relatively high affinity for Fn. This also suggests that $\mathrm{Fn}$, which is deposited by the cells, will not easily be exchanged for other proteins present in the culture medium.

After exposure of polymer surfaces to solutions of low serum concentration (or no serum at all), a direct adhesion with incomplete spreading of HEC to the material surface occurs which made the detachment of the cells by trypsinization difficult. This direct adhesion also depends on surface wettability, since decreasing numbers of HEC adhered to PETP and FEP as compared to TCPS. Such a cell adhesion probably occurs through attraction of cells by polar- and/or hydroxyl groups on the modified TCPS surface (which is possibly glow discharge treated polystyrene).

Fn adsorption onto materials from plasma was also reported to be maximal after diluting plasma to $0.1 \%{ }^{11}$

Experiments carried out by Grinnell ${ }^{11}$ showed that Fn also adsorbs to surfaces from whole blood. He observed a marked increase in Fn deposition on surfaces if the blood were clotted by the addition of thrombin or $\mathrm{Ca}^{2+}$. Fn adsorption to polymer surfaces from whole blood may be important with regard to HEC overgrowth and biocompatibility of vascular grafts. This is indicated by the observation that Fn precoating of Dacron and Teflon vascular grafts, in combination with endothelial cell seeding, improves the in vitro and in vivo endothelialization rate of such grafts, ${ }^{38-40}$ when compared to uncoated grafts.

It is not yet known, whether vascular grafts made of moderately wettable polymers adsorb more Fn from whole blood than vascular grafts made of hydrophobic materials. In this respect one observation seems relevant: the grafting of acrylic acid onto woven Dacron, which resulted into moderately wettable grafts, showed a significant haemotolerant and haemodynamic improvement during one year follow-up studies. ${ }^{41}$

From our results it is concluded that TCPS, in contrast to PETP and FEP, gives rise to the adsorption of serum proteins which favor the adhesion of HEC. Of the polymer surfaces studied, adsorption of Fn only occurs onto TCPS, with a maximum at $0.1 \%$ serum concentration. Maximal cell adhesion onto TCPS is also observed after exposure to a solution containing $0.1 \%$ serum. Alb and HDL, which inhibit or delay cell adhesion, preferentially adsorb after pretreatment of TCPS with solutions of higher serum concen- 
tration, thereby decreasing the cell adhesion. After desorption of proteins which inhibit cell adhesion and their replacement by, e.g., cellular Fn, cell spreading upon TCPS may start. Endothelialization of PETP and FEP only occurs after precoating with proteins which promote cell adhesion, such as Fn.

We thank Ir. G. J. te Meerman from the State University of Groningen, The Netherlands, for carrying out the statistical analysis of our results.

\section{References}

1. S. M. Lindenauer, "Experimental evaluation of Dacron knitted vascular grafts," in Biologic and Synthetic Vascular Prostheses, J.C. Stanley, Ed., Grune and Stratton, New York, 1982, pp. 523-532.

2. M. Herring, A. Gardner, and J. Glover, "A single staged technique for seeding vascular grafts with autogenous endothelium," Surgery, 84 498-504 (1978).

3. W. E. Burkel, "Endothelial seeding of enzymatically derived and cultured cells on prosthetic grafts," Biologic and Synthetic Vascular Prostheses, Vol. 38, J. C. Stanley, Ed., Grune and Stratton, New York, 1982, pp. 631-651.

4. F. Grinnell, "Cellular adhesiveness and extracellular substrates," Int. Rev. Cytol., 53, 65-144 (1978).

5. L. Weiss, "The adhesion of cells," Int. Rev. Cytol., 9, 187-225 (1960).

6. R. E. Baier, "Adhesion: mechanisms that assist or impede it," Science, 162, 1360-1368 (1968).

7. F. Grinnell and M.K. Feld, "Initial adhesion of human fibroblasts in serum-free medium: possible role of secreted fibronectin," Cell, 17, 117-129 (1979).

8. E. A. Jaffe and D. F. Mosher, "Synthesis of fibronectin by cultured endothelial cells," J. Exp. Med., 147, 1779-1791 (1978).

9. E. Ruoslahti, M. Pierschbacher, E. G. Hayman, and E. Engvall, "Fibronectin: a molecule with remarkable structural and functional diversity," TIBS, 188 (1982).

10. F. Grinnell and M. K. Feld, "Fibronectin adsorption on hydrophilic and hydrophobic surfaces detected by antibody binding and analyzed during cell adhesion in serum-containing medium," J. Biol. Chem., 257, 9, 4888-4893 (1982).

11. F. Grinnell and T. P. Phan, "Deposition of fibronectin on material surfaces exposed to plasma: Quantitative and biological studies," J. Cell. Phys., 116, 289 (1983).

12. F. Grinnell, "The role of fibronectin in the bioreactivity of material surfaces," in Biocompatible Polymers, Metals, and Composites, M. Szycher, Ed., Technomic Publ. Co., Lancaster, Pa, 1983, pp. 673-699.

13. A. S. G. Curtis, J. V. Forrester, C. McInnes, and F. Lawrie, "Adhesion of cells to polystyrene surfaces," $]$. Cell. Biol., 97, 1500-1506 (1983).

14. P. Knox, "Kinetics of cell spreading in the presence of different concentrations of serum or fibronectin depleted serum," I. Cell. Sci., 71, 51-59 (1984).

15. K. L. Bently and J. Klebe, "Fibronectin binding properties of bacteriologic petri plates and tissue culture dishes," I. Biomed. Mat. Res., 19, 757-769 (1985).

16. P. H. Burrill, I. Bernardini, H. K. Kleinman, and N. Kretchmer, "Effect of serum, fibronectin and laminin on adhesion of rabbit intestinal epithelial cells in culture," J. Supramol. Struct. Cell. Biochem., 16, 385-392 (1981). 
17. T. A. Horbett, M. B. Schway, and B.D. Ratner, "Hydrophilichydrophobic copolymers as cell substrates: effect on 3T3 cell growth rates," J. Colloid Interface Sci, 104, 28-39 (1985).

18. A.S. G. Curtis and J. V. Forrester, "The competitive effects of serum proteins on cell adhesion," J. Cell Sci, 71, 17-33 (1984).

19. J. Feijen, T. Beugeling, A. Bantjes, and C. Th. Smit Sibenga, "Biomaterials and interfacial phenomena," Adv. Phys., 3, 100 (1979).

20. P. B. van Wachem, T. Beugeling, J. Feijen, A. Bantjes, J. P. Detmers, and W. G. van Aken, "Interaction of cultured human endothelial cells with polymeric surfaces of different wettabilities," Biomaterials, 6, 403-408 (1985).

21. P. B. Van Wachem, T. Beugeling, J. Feijen, A. Bantjes, J. P. Detmers, and W. G. Van Aken, Life Support Systems, Proc. XIth Annual Meeting ESAO, W. B. Saunders, Eastbourne, U.K., 1984, pp. 98-102.

22. W. Breemhaar, D. L. Ellens, T. Beugeling, and A. Bantjes, "A novel application of a two step enzyme-immunoassay for the investigation of blood compatibility of materials. Life Support Systems, Proc. IXth Annual Meeting ESAO, W. B. Saunders Co., Eastbourne, U.K., 1982, pp. 295-300.

23. W. Breemhaar, E. Brinkman, D. J. Ellens, T. Beugeling, and A. Bantjes, "The interaction of polymers and blood plasma: preferential adsorption of high density lipoprotein from blood plasma onto biomaterial surfaces," Biomaterials, 5, 269-274 (1984).

24. E. Ruoslahti, E. G. Hayman, M. Pierschbacher, and E. Engvall, "Fibronectin: purification, immunological properties and biological activity," Methods Enzymol., 82, 803-831 (1982).

25. E. A. Jaffe, L. W. Hoyer, and R. L. Nachman, "Synthesis of antihemophilic factor antigen by cultured human endothelial cells," J. Clin. Invest., 52, 2757-2764 (1973).

26. E. A. Jaffe, R. L. Nachman, C. G. Becker, and C. R. Minick, "Culture of human endothelial cells derived from umbilical veins. Identification by morphologic and immunologic criteria," I. Clin. Invest., 52, 2745 (1973).

27. Ch. Willems, G. C. B. Astaldi, Ph. G. de Groot, M.C. Janssen, M. D. Gonsalves, W. P. Zeijlemaker, J. A. van Mourik, and W. G. van Aken, "Media conditioned by cultured vascular smooth muscle cells," Exp. Cell. Res., 139, 191 (1982).

28. Ph. G. Groot, Ch. Willems, M. D. Gonsalves, W. G. van Aken, and J. A. van Mourik, "The proliferation of human umbilical cord vein endothelial cells in serum-free medium," Thromb. Res., 31, 623-634 (1983).

29. Z. M. Ruggeri, P. M. Mannucci, S. L. Jeffcoate, and G.I.C. Ingram, "Immunoradiometric assay of factor VIII related antigen, with observations in 32 patients with von Willebrands disease," Br.J. Haematol., 33, 221-232 (1976).

30. H. V. Stel, K. S. Sakariassen, B. J. Scholte, E. C. I. Veerman, Th. H. van der Kwast, Ph. G. de Groot, J.J. Sixma, and J. A. van Mourik, "Characterization of 25 monoclonal antibodies to factor VIII-von Willebrand factor: relationship between ristocetin-induced platelet aggregation and platelet adherence to subendothelium," Blood, 63, 1408-1415 (1984).

31. J. A. Salmon, "A radioimmunoassay for 6-keto-prostaglandin F1 $\alpha$," Prostaglandins, 15, 383-397 (1978).

32. R. J. Klebe, K. L. Bently, and R.C. Schoen, "Adhesive substrates for fibronectin," J. Cell. Physiol., 109, 481-488 (1981).

33. P. Knox and S. Griffiths, "The distribution of cell-spreading activities in sera: a quantitive approach," J. Cell Sci., 46, 97 (1980).

34. P. Knox and S. Griffiths, "The abnormal morphology of polyomatransformed baby hamster kidney cells is due to a failure to respond to 70K spreading factor," J. Cell Sci., 55, 301 (1982). 
35. E. Ruoslahti, M. D. Pierschbacher, S. Suzuki, R. Pytela, C. R. Ill, and E. G. Hayman, "Serum adhesive proteins: molecular anatomy of the cell adhesion-promoting activity of fibronectin and related adhesion proteins," Abstract 326, Xth International Congress on Thrombosis and Haemostasis, San Diego, CA, USA, July 14-19, 1985.

36. D. F. Mosher, M.J. Doyle, and E. A. Jaffe, "Synthesis and secretion of thrombospondin by cultured human endothelial cells," J. Biol. Chem., 93, 343 (1982).

37. J. H. Reinders, Ph. de Groot, J. Dawes, N. R. Hunter, H. A. A. van Heugten, J. Zandbergen, M. D. Gonsalves, and J. A. van Mourik, “Von Willebrand factor, thrombospondin and fibronectin of cultured vasular endothelial cells, Abstract 1152," Xth International Congress on Thrombosis and Haemostasis, San Diego, CA, USA, July 14-19, 1985.

38. K.A. Kesler and M.P. Herring, "Enhanced strength of endothelial attachment on polyester elastomer and polytetrafluoroethylene graft surfaces with fibronectin substrate," The International Society for Cardiovascular Surgery, Baltimore, June 6-7, 1985.

39. J. M. Seeger and N. Klingman, "Improved endothelial cell seeding with cultured cells and fibronectin-coated grafts," J. Surg. Res., 38(6), 641-647 (1985).

40. R. F. Kempczinski, G. R. Ramalanjaona, J. E. Rosenman, E. C. Douville, and E. B. Silberstein, "Effect of fibronectin-coating on endothelial cell kinetics in PTFE grafts," The International Society for Cardiovascular Surgery, Baltimore, June 6-7, 1985.

41. R. M. Miller, D.E. M. Taylor, B.S. Ringrose, and P. Fydelor, "Haemodynamic effects of copolymerisation with acrylic acid on woven Dacron arterial prostheses," Abstract 136, 12th Annual Meeting ESAO, Athens, Greece, September, 1985.

Received July 14, 1986

Accepted October 30, 1986 